\title{
A Control Strategy for Smoothing Active Power Fluctuation of Wind Farm with Flywheel Energy Storage System Based on Improved Wind Power Prediction Algorithm*
}

\author{
J. C. Wang, X. R. Wang ${ }^{\#}$ \\ School of Electrical Engineering, Southwest Jiaotong University, Chengdu, China \\ Email: *x_r_wang@163.com
}

Received March, 2013

\begin{abstract}
The fluctuation of active power output of wind farm has many negative impacts on large-scale wind power integration into power grid. In this paper, flywheel energy storage system (FESS) was connected to AC side of the doubly-fed induction generator (DFIG) wind farm to realize smooth control of wind power output. Based on improved wind power prediction algorithm and wind speed-power curve modeling, a new smooth control strategy with the FESS was proposed. The requirement of power system dispatch for wind power prediction and flywheel rotor speed limit were taken into consideration during the process. While smoothing the wind power fluctuation, FESS can track short-term planned output of wind farm. It was demonstrated by quantitative analysis of simulation results that the proposed control strategy can smooth the active power fluctuation of wind farm effectively and thereby improve power quality of the power grid.
\end{abstract}

Keywords: Wind Power Generation; FESS; Wind Power Prediction; Improved Time-series Algorithm; Active Power Smooth Control

\section{Introduction}

With large-scale wind power integration into grid, the fluctuation of active power output of wind farm has turned the operation and control of power system much more difficult [1]. It's shown by researches that the wind power fluctuation of various time scales will have different impacts on different aspects of power system, such as power quality, system reserve capacity, energy dispatching, etc. $[2,3]$. Therefore, the study on smooth control of active power of wind farm contributes to improve the power supply reliability of wind power integration and the level of accepting large-scale wind power by system [4].

As an effective measure to smooth the fluctuation of wind power, energy storage technology has drawn more and more attention [5]. Making the output active power of wind turbine to track given smooth power curve by controlling generator speed and pitch would reduce wind energy utilization efficiency [6, 7]. Instead, energy storage device doesn't have such a weakness. In references

\footnotetext{
"Project support refers to acknowledgements.

"Corresponding author.
}

$[8,9]$, the Battery Energy Storage System (BESS) has smoothed the wind power fluctuation. However, the BESS has some shortcomings, such as high cost, heavy environmental pollution and high period maintenance expense etc. [3,10]. By contrast, flywheel energy storage system (FESS) is features with rapid charging and discharging, long periodic service life and environmental pollution free, which is applicable to smooth short-term wind power fluctuation [11]. In reference [12, 13], FESS is used to realize smooth control over active power output of wind farm. A FESS is designed and a reference power calculation method based on filter is studied to determine the operation state of the FESS in reference [13]. However, in these control methods, the role of FESS to track planned output of wind power has not been taken into consideration and corresponding control strategies are seldom discussed in research.

This paper proposed a new FESS control strategy applicable to smooth short-term wind power fluctuation on the platform of doubly-fed induction generator (DFIG) and FESS power generation system. Reference power of FESS is given based on improved ultrashort-term wind power prediction algorithm and power curve modeling. 
The energy storage system can track short-term planned output power of wind farm and smooth the wind power fluctuation simultaneously. A simulation system referred to reference [13] was established on the Matlab/Simulink for analysis, which proved the correctness and effectiveness of the proposed smooth control strategy.

\section{Power Generation System with FESS}

Refer to Figure 1 for the structure of power generation system with FESS ${ }^{[14]}$. The system is composed of DFIG wind farm, synchronous generator (power grid) as well as load and FESS. FESS is connected to AC side of the wind farm converter. The FESS contains drive motor, flywheel rotor, bearing support system, converters, etc. High-speed permanent magnet synchronous motor (PMSM) is adopted as drive motor for FESS to ensure wide speed range and rapid dynamic response. Flywheel rotor acceleration to charge and its deceleration to discharge can be realized by controlling the PMSM. Thus, mutual transfer between electric energy and mechanical energy can be achieved. Converters of both the FESS and the DFIG can be controlled to implement maximum power point tracking (MPPT) of the wind turbine and smooth the output power of wind farm to some extent.

\section{Active Power Smooth Control}

\subsection{Wind Power Prediction Algorithm}

The smooth control strategy is based on ultrashort-term wind power prediction algorithm. FESS is used to track the predicted wind power [15] and to smooth the high frequent and irregular output power fluctuation. The ultrashort-term wind power prediction algorithm mainly includes persistence approach [16], time-series algorithm [17], wind speed-power curve modeling [18], etc. Timeseries algorithm was used in this paper to predict wind speed, owning to the persistence of wind speed and other atmospheric conditions within a short period [16] and fewer input parameters necessary for time-series algorithm. Then, in accordance with the relationship between actual wind power and corresponding sequential wind speed, a model was built to convert predicted wind speed into predicted wind power.

Refer to the following for the process of wind speed prediction algorithm.

Step1. Wind speed $v(t)$ from supervisory control and data acquisition (SCADA) of wind farm is used as input. Step-length sequential wind speed before current time $t$ is read as input and stored in the data structure of Map.

Step2. Initialize weight parameters and learning rate with least square method; normalize data in Map.

Step3. Predict wind speed at time $t+1$ with time-series algorithm and reverse normalize results.

Step4. Update weights; $\mathrm{t}=\mathrm{t}+1$.
If multistep prediction is processed, the predicted wind speed at time $t+i$ shall be used as actual wind speed at time $\mathrm{t}+\mathrm{i}$ for input to obtain the predicted wind speed of i-length after time $t$.

From the perspective of overall property, the power characteristic piecewise function for wind turbine in reference [19] can be simplified as Equation (1):

$$
P(v)=\left\{\begin{array}{l}
f(v), 0 \leq v<v_{\text {cut }- \text { off }} \\
0, v \geq v_{\text {cut-off }}
\end{array}\right.
$$

Wind Power characteristic curve is $f(v)$ when actual wind speed is between 0 and cut-out wind speed. $f(v)$ can be fitted through scatter diagram of actual wind power and corresponding sequential wind speed. Trust region method based on nonlinear minimization is used for curve fitting. Figure $2(f(v)$ section) is shown the scatter points of actual wind speed and power as well as the fitting curve of a typical DFIG (Rated capacity $1.5 \mathrm{MW}$ and rated wind speed $15 \mathrm{~m} / \mathrm{s}$ ).

The fitted function is Equation (2):

$$
f(v)=-0.0007723 v^{3}+0.0391 v^{2}-0.4298 v+1.197
$$

Residual sum of squares (RSS), R-square, adjusted R-square, and root-mean-square error (RMSE) are introduced as indexes for evaluating curve fitting effect [18].

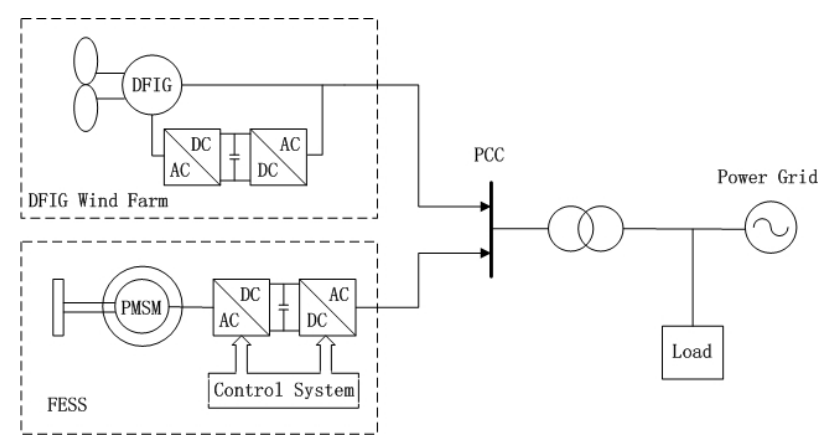

Figure 1. Power generation system with FESS.

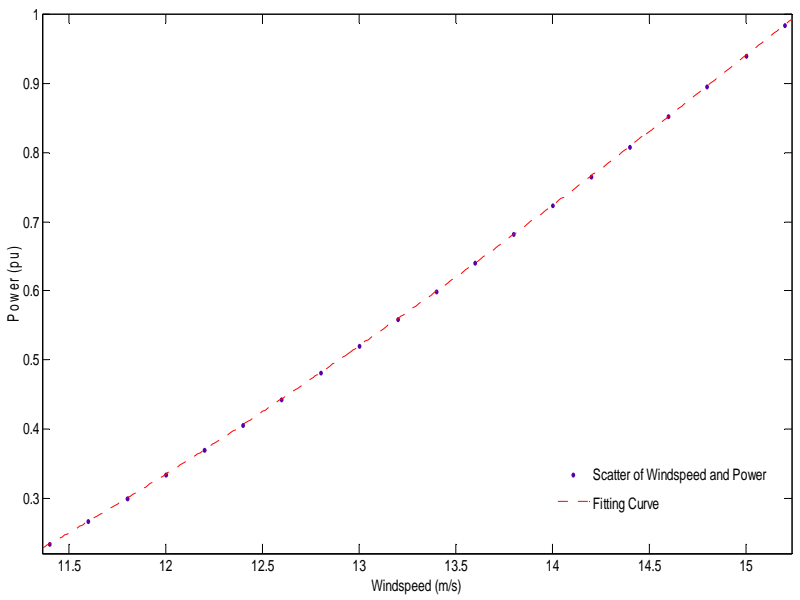

Figure 2. Fitting curve of a typical DFIG. 
RSS $=6.418$, R-square $=0.9774$, Adjusted R-square $=$ $0.9771, \mathrm{RMSE}=0.2119$. The closer RSS and RMSE to 0 and R-square and adjusted R-square to 1 , the better the curve fitting effect will be. Therefore, it can be seen that the simplified model can fit wind speed-power scatter favorably, converting predicted wind speed to predicted power of wind turbine.

Consider the complicated real-time dispatching of wind farm, the following improvements have been made based on the aforementioned ultrashort-term prediction algorithm.

1) Simulate a stop command when the wind turbine is under overhaul condition. If this command works, no ultrashort-term prediction will be carried out.

2) Suppose that the real-time power of wind turbine at current time $\mathrm{t}$ is 0 and the planned stop time is $\mathrm{t} 2(\mathrm{t} 2>\mathrm{t})$, if $(\mathrm{t} 2-\mathrm{t})$ is smaller than the selected length of prediction step, persistence approach shall be used to predict within time range $(\mathrm{t} 2-\mathrm{t})$, i.e. the predicted power equals to real-time power of previous moment.

3) The phenomenon that wind speed is smaller than cut-in speed leads to the stop of wind turbine. Probability model shall be used for determination in this situation. Analyze the points that wind turbine power was 0 and corresponding wind speed was less than cut-in wind speed $(3 \mathrm{~m} / \mathrm{s})$ from Jan. 2012 to Sept. 2012 of one wind farm (hereinafter referred to as stop point). Find out 3 consecutive wind speed points (named as the point 1 , the point 2 and the point 3 , the point 3 is the point closest to the stop point on time axis) before stop points. Each 3 points makes a group. Figure $\mathbf{3}$ has demonstrated the frequency number distribution drawing of all 3 consecutive points in front of the stop points of one wind turbine in wind farm from Jan. 2012 to Sept. 2012.

It can be seen from above figure that the wind speed of almost all points is less than $4 \mathrm{~m} / \mathrm{s}$. Calculate the descent rate between 3 points in each group, i.e. (Point 1-Point
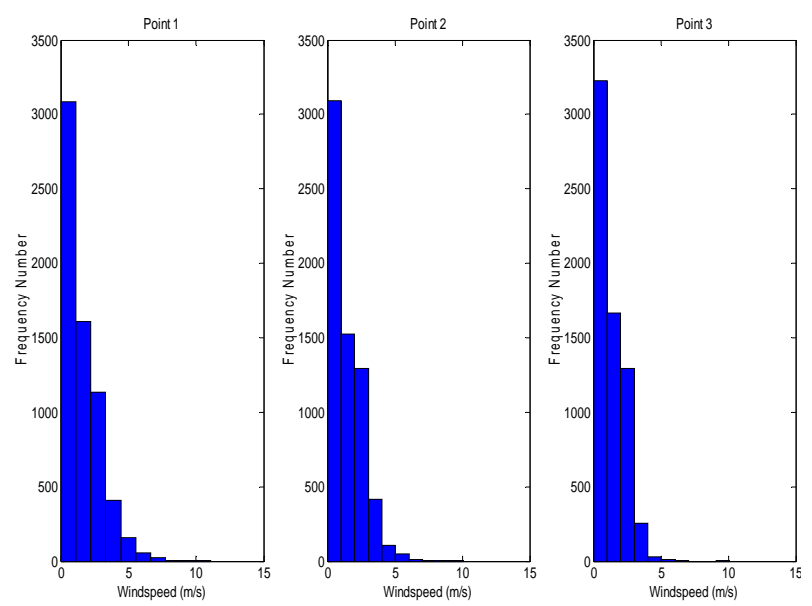

Figure 3. 3 consecutive points in front of the stop points wind speed frequency number distribution.
2) $/ \Delta \mathrm{t}$, (Point 2-Point 3) $/ \Delta \mathrm{t}$. $\Delta \mathrm{t}$ is sample interval. It's shown that almost all rate of descent is larger than +1.1 . Other wind turbines of the wind farm have the similar distribution characteristics. Therefore, suppose that the real-time wind speed of single wind turbine at current time $\mathrm{t}$ is wind speed [ $\mathrm{t}$ ], if two consecutive wind speed sampling points before $\mathrm{t}$ is wind speed $[\mathrm{t}-\Delta \mathrm{t}]$ and windspeed $[\mathrm{t}-2 \Delta \mathrm{t}]$ satisfy Equation (3), the predicted power at time $\mathrm{t}+1$ is 0 .

$$
\left\{\begin{array}{l}
\text { windspeed }[t]<4 m / s \\
\text { windspeed }[t-\Delta t]<4 m / s \\
\text { windspeed }[t-2 \Delta t]<4 m / s \\
(\text { windspeed }[t-\Delta t]-\text { windspeed }[t]) / \Delta t>1.1 \\
(\text { windspeed }[t-2 \Delta t]-\text { windspeed }[t-\Delta t]) / \Delta t>1.1
\end{array}\right.
$$

\subsection{Smooth Control Strategy}

The principle for controlling the active power of wind farm with FESS is as follows: when wind energy is affluent, surplus energy will be converted into kinetic energy and be stored in the flywheel through charging process with increasing rotate speed. When wind power decreases or active power of the system is deficient, lowing rotate speed to release stored energy to stabilize the output power of wind farm around target value. Suppose that actual output power of wind farm is $P_{w f}$ and the target power of wind farm with FESS is $P_{\text {expect }}$, the reference power for FESS is Equation (4):

$$
P_{r e f}=P_{\text {expect }}-P_{w f}
$$

when $P_{\text {ref }}>0$, flywheel is operating as electromotor; when $P_{\text {ref }} \leq 0$, flywheel is operating as generator. In order to make the wind farm output as target power $P_{\text {expect }}$, i.e. the key is the calculation method for $P_{\text {expect }}$ and the control of reference power of FESS. Generally, in traditional $P_{\text {expect }}$ calculation, a relatively smooth curve can be obtained from actual wind farm output power $P_{w f}$ through low pass filter $[20,21]$.

A new $P_{\text {expect }}$ smooth calculation method was proposed in this paper based on forenamed ultrashort-term wind power prediction algorithm. Firstly, the average wind speed $v_{\text {average }}$ is defined as Equation (5):

$$
v_{\text {average }}=\left(\int_{t-\tau}^{t} v(t) d t\right) / \tau
$$

wherein, $t$ is current time, $\tau$ is integration interval and $t \geq \tau$.

$v(t)$ is calculated by actual wind speed series through above mentioned prediction algorithm. Input average wind speed calculated by equation (5) into fitted power curve $f(v)$ to obtain $P_{\text {expect }}$, i.e. $P_{\text {expect }}=f\left(v_{\text {average }}\right)$, $P_{\text {ref }}$ of FESS shall be controlled to output compound power as the smoothed power $P_{\text {expect }}$. Thus, the wind 
power fluctuation is leveled. The prediction horizon is $\mathrm{F}$ and its length is not less than control horizon $\mathrm{m}$. In this paper, $\mathrm{F}=\mathrm{m}=30 \mathrm{~s}$. The prediction sample interval is integral multiple of simulation step of the system. Figure 4 has displayed the actual wind speed curve of wind farm and corresponding predicted wind speed and average wind speed. There is an integrating process from the $0 \mathrm{~s}$ to around $1.2 \mathrm{~s}$.

The smoothness of $P_{\text {expect }}$ can be changed through adjusting integration interval $\tau$. As for wind farm with multiple sets of wind turbines, if the distribution form of wind turbines and wake effect are not be taken into account, approximately $P_{\text {expect }}=k \cdot f\left(v_{\text {average }}\right)$, wherein, $\mathrm{k}$ represents sets of wind turbines. The essence of given reference power is the smoothing of predicted power. Combined with wind power prediction technology, FESS track the planned output power of wind farm to same degree and smooth the irregular fluctuation of wind power. The accuracy for $P_{\text {expect }}$ to track the planned output of wind farm is decided by the precision of wind power prediction. The introduction of FESS reduces the increased system reserve capacity due to the error of wind power prediction and smoothes the wind power output simultaneously, which contributes to the operation management of power system dispatching department to wind farm.

\subsection{Control of the FESS}

PMSM, used as drive motor for FESS, is adopted the control method of maximum torque per ampere (MPTA) [22] to make the stator current vector orthogonal with rotor axis in reverse direction. i.e. $i_{s q}=0$ and electromagnetic torque is $T_{e}=1.5 P_{m} \psi_{f} i_{s q}$. A linear relation is formed between electromagnetic torque and stator current on $q$ axis component. Control $i_{s q}$ to adjust the torque $T_{e}$, thereby, the reference power $P_{\text {ref }}$ of FESS can be controlled. Converter at motor side is controlled by space vector pulse width modulation (SVPWM). And converter at power grid side is adopted the double closed-loop control of voltage and current.

When calculating reference power, rotor speed limit of flywheel shall be taken into consideration. It's set that FESS can operate normally only when the rotor speed $w$ is higher than minimum rotor speed and reference power is less than or equals to 0 , or the rotor speed is lower than the maximum rotor speed and reference power is larger than 0 [23].

To avoid repeated accelerating of flywheel, new control rules are set as: (1) when FESS is operating normally, reference torque of the FESS is $T_{\text {ref }}=P_{\text {ref }} / w+B \cdot w_{m}$; $B$ is friction coefficient and $w_{m}$ is rated rotor speed of the FESS; (2) When the rotor speed reaches maximum speed and $P_{r e f}>0$, the reference torque is $T_{r e f}=B \cdot w_{m}$;
(3) When $P_{r e f} \leq 0$ and rotor speed reduces to minimum speed, the reference torque is 0 and the FESS stops generating.

\section{Simulation}

Established the simulation platform is shown in Figure 1 in Matlab/Simulink. Refer to simulation parameters setting in reference [13]. The wind farm contains 12 DFIGs with a rated capacity of $1.5 \mathrm{MW}$ and rated wind speed 15 $\mathrm{m} / \mathrm{s}$. Power grid is composed of 1 synchronous generator (SG). The maximum output power of FESS is 6MW and simulation time is $30 \mathrm{~s}$. Refer to Table $\mathbf{1}$ for other main simulation parameters.

Under wind speed fluctuation shown in Figure 4, actual power output curve of wind farm without FESS and compound power curve of wind farm with FESS using aforementioned control strategy are shown in Figure 5. Surge current of wind turbine will generate when starting the simulation model. After $1.7 \mathrm{~s}$, the system is stable.

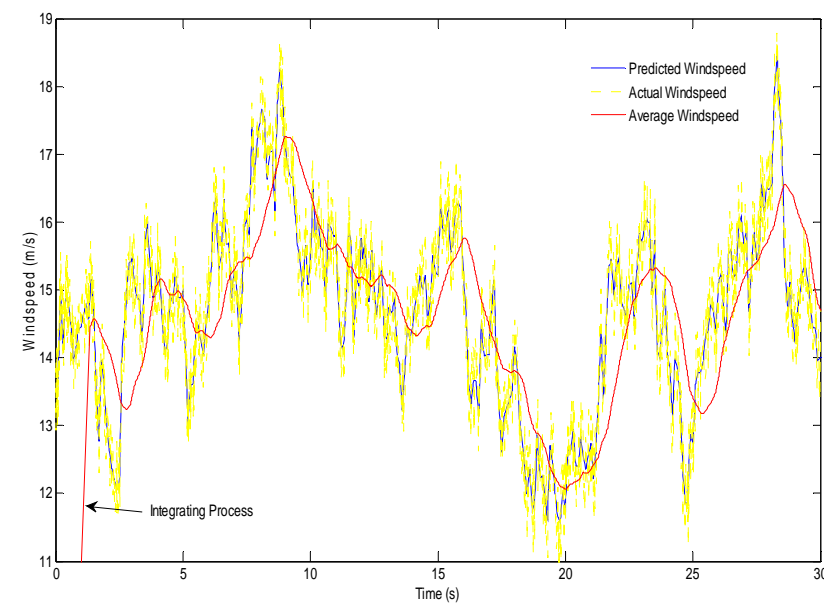

Figure 4. Curves of wind speed and average wind speed.

Table 1. Main parameters of the simulation system.

\begin{tabular}{ccc}
\hline \multirow{2}{*}{ Devices } & \multicolumn{2}{c}{ Simulation Parameters } \\
\cline { 2 - 3 } & Parameter & Value \\
\hline \multirow{2}{*}{ FESS } & Initial speed & $600 \mathrm{~kg} \cdot \mathrm{m}^{2}$ \\
& Friction coefficient & $4000 \mathrm{rpm}$ \\
DFIG & Rated voltage & $\mathrm{N} \cdot \mathrm{m} \cdot \mathrm{s} \cdot \mathrm{rad}^{-1}$ \\
& Maximum output power & $575 \mathrm{~V}$ \\
& Rated voltage & $1.75 \mathrm{MW}$ \\
& Rated power & $13.8 \mathrm{kV}$ \\
& Number of pole-pairs & 32 \\
\hline
\end{tabular}


And then, two indicators are introduced to determine the smoothness of active power output.

1) Maximum fluctuation of compound output power of wind power and energy storage shall not exceed $10 \%$ of rated capacity of wind farm $P_{\text {rated }}$ within any 20 minutes. During the simulation time after stable operation of the system, the difference between maximum and minimum compound output power is $9.3 \mathrm{MW}$, far less than rated capacity of wind farm $18 \mathrm{MW}$. It can be concluded from Figure 5 that smooth control strategy with FESS has reduced the duration when the output power of wind farm is higher than the rated power.

2) Define smooth coefficient [12] as Equation (6):

$$
\text { Smooth }=\left(\int_{0}^{t}\left|d P_{w f} / d t\right| d t\right) / P_{\text {rated }}
$$

The smaller the gradient of smooth coefficient curve, the smoother active power output to power grid. Refer to Figure 6 for smooth coefficient curve with/without FESS.

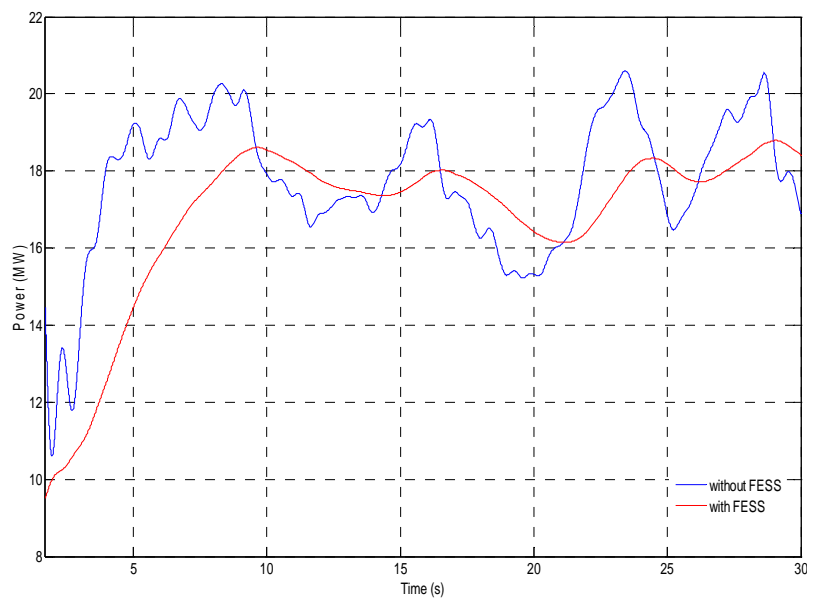

Figure 5. Curve of active power output of wind farm with/ without FESS (From 1.7s).

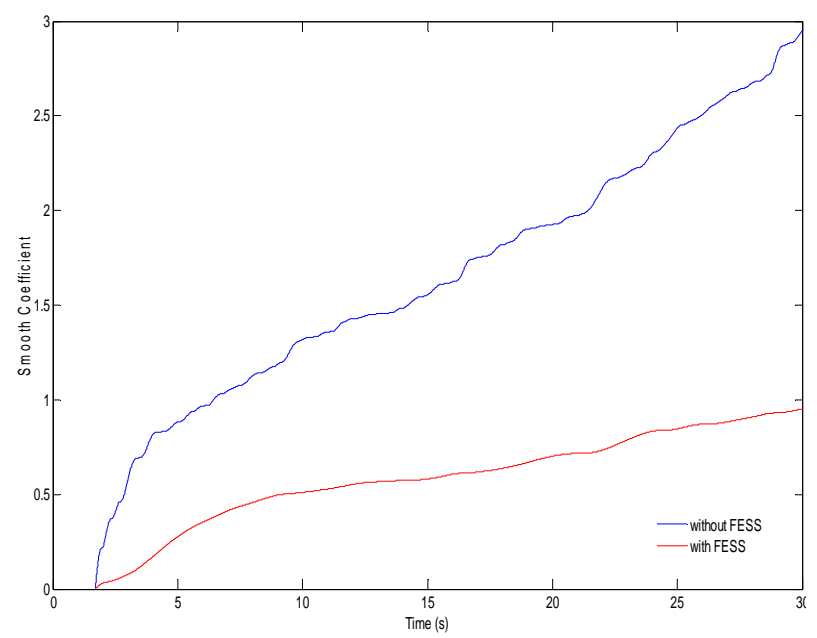

Figure 6. Curves of smooth coefficient with/without FESS.
It can be seen from above figure that there is larger fluctuation in active power output of wind farm without FESS even though DFIG is operating under the control strategy of MPPT. After using FESS, the proposed control strategy reduces wind power fluctuation significantly without affecting wind energy utilization efficiency. The smooth coefficient is only $25 \%$ of that without FESS.

\section{Conclusions}

In this paper, a smooth control strategy for active power of wind farm with FESS was realized. Meanwhile, the demand of power grid dispatch for wind power prediction was also taken into consideration. A new calculation method for FESS reference power was proposed based on improved wind power prediction algorithm and power curve modeling. From the quantitative analysis of simulation results, it could be concluded that the proposed control strategy would smooth the fluctuation of wind power effectively and track short-term planned output power of wind farm favorable. Therefore, the smooth control strategy has improved schedulability of wind farm, which contributes to the stable operation of power grid. However, the effects that the precision of wind power prediction and energy storage capacity act on the control of active wind power need a further study.

\section{Acknowledgements}

This work is supported by National Natural Science Foundation (NNSF) of China under Grant 50937002 and by the Fundamental Research Funds for the Central Universities under Grant SWJTU09ZT10.

\section{REFERENCES}

[1] Y. Z. Sun, J. Wu and G. J. Li, "Influence Research of Wind Power Generation on Power Systems," Power System Technology, Vol. 31, No. 20, 2007, pp. 55-62.

[2] H. Holttinen and R. Hirvonen, "Wind Power in Power Systems," 1st Edition, John Wiley \& Sons Ltd., Chichester, 2005.

[3] Q. Xiong and L. Liao, "Power Smoothing Control Strategy for Direct-driven Wind Power System with Flywheel Energy Storage System," East China Electric Power, Vol. 40, No. 9, 2012, pp.1533-1539.

[4] Y. C. Xue, N. L. Tai, K. Song, et al., "Smoothing Control Strategy on Power Fluctuation of Power Filtering Based Wind Farm," East China Electric Power, Vol. 39, No. 3, 2011, pp. 454-458.

[5] J. P. Barton and D. G. Infield, "Energy Storage and its Use with Intermittent Renewable Energy," IEEE Transactions on Energy Conversion, Vol. 19, No. 2, 2004, pp. 441-448. doi:10.1109/TEC.2003.822305

[6] L. Changling, H. Banakar, S. Baike, et al., "Strategies to Smooth Wind Power Fluctuations of Wind Turbine Gen- 
erator," IEEE Transactions on Energy Conversion, Vol. 22, No. 2, 2007, pp. 341-349. doi:10.1109/TEC.2007.895401

[7] Y. Liao, J. B. He, J. Yao, et al., "Power Smoothing Control Strategy of Direct-driven Permanent Magnet Synchronous Generator for Wind Turbine With Pitch Angle Control and Torque Dynamic Control," Proceedings of the CSEE, Vol. 29, No. 18, 2009, pp. 71-77.

[8] D. Q. Bi, B. M. Ge and W. L. Wang, "VRB Energy Storage System Based Power Control of Grid-connected Wind Farm," Automation of Electric Power Systems, Vol. 34, No. 13, 2010, pp. 72-78.

[9] H. S. Hong, Q. Y. Jiang and Y. T. Yan, “An Optimization Control Method of Battery Energy Storage System with Wind Power Fluctuations Smoothed in Real Time," $\mathrm{Au}$ tomation of Electric Power Systems, Vol. 37, No. 1, 2013, pp. 103-109.

[10] B. Li and J. B. Guo, "A Control Strategy for Battery Energy Storage System to Level Wind Power Output," Power System Technology, Vol. 36, No. 8, 2012, pp. 38-43.

[11] J. P. Ruan, J. C. Zhang and J. H. Wang, "Improvement of Stability of Wind Farms Connected to Power Grid Using Flywheel Energy Storage System," Electric Power Science and Engineering, Vol. 24, No. 3, 2008, pp. 5-8.

[12] X. S. Hu, C. X. Sun, R. Liu, et al., "An Active Power Smoothing Strategy for Direct-driven Permanent Magnet Synchronous Generator Based Wind Turbine Using Flywheel Energy Storage," Automation of Electric Power Systems, Vol. 34, No. 13, 2010, pp. 79-83.

[13] R. Xiang, X. R. Wang and J. Tan, "Operation Control of Flywheel Energy Storage System Applying to Wind Farm," Journal of Systems Science and Mathematical Sciences, Vol. 32, No. 4, 2012, pp. 438-449.

[14] R. Takahashi and J. Tamura, "Frequency Control of Isolated Power System with Wind Farm by Using Flywheel Energy Storage System," Proceedings of the 18th International Conference on Electrical Machines of the ICEM, Vilamoura, 6-9 September 2008, pp. 1-6.

[15] P. Jiang and H. C. Xiong, "A Control Scheme Design for
Smoothing Wind Power Fluctuation with Hybrid Energy Storage System," Automation of Electric Power Systems, Vol. 37, No. 1, 2013, pp. 122-127.

[16] M. Lei, L. Y. Shi, W. J. Chuan, et al., "A Review on the Forecasting of Wind Speed and Generated Power," Renewable and Sustainable Energy Reviews, Vol. 13, No. 4, 2009, pp. 915-920. doi:10.1016/j.rser.2008.02.002

[17] K. Chang, M. S. Ding, F. Xue, et al., "Ultra-short-term Wind Power Prediction and its Application in Early-warning System of Power Systems Security and Stability," Power System Protection and Control, Vol. 40, No. 12, 2012, pp. 19-24.

[18] J. F. Li, B. H. Zhang, G. L. Xie, et al., "Grey Predictor Models for Wind Speed-Wind Power Prediction," Power System Protection and Control, Vol. 38, No. 19, 2010, pp. 151-159.

[19] W. Wangdee and R. Billinton, "Considering Load-carrying Capability and Wind Speed Correlation of WECS in Generation Adequacy Assessment," IEEE Transactions on Energy Conversion, vol. 21, No. 3, 2006, pp. 734-741. doi:10.1109/TEC.2006.875475

[20] T. Tanabe, T. Sato, R. Tanikawa, I. Aoki, T. Funabashi and R. Yokoyama, "Generation Scheduling for Wind Power Generation by Storage Battery System and Meteorological Forecast," Proceedings of the Power and Energy Society General Meeting - Conversion and Delivery of Electrical Energy in the 21st Century of the IEEE, Pittsburgh, PA, 20-24 July 2008, pp. 1-7.

[21] J. V. Paatero and P. D. Lund, "Effect of Energy Storage on Variations in Wind Power," Wind Energy, Vol. 8, No. 4, 2005, pp. 421-441. doi:10.1002/we. 151

[22] X. Z. Tang, "Vector Control System of Permanent -Magnet Synchronous Motor," Master Thesis, Zhejiang University, Zhejiang, 2005.

[23] C. Chapelsky, J. Salmon and A. Knight, "Control of a High-Inertia Flywheel as Part of a High Capacity Energy Storage System," Proceedings of the Canadian Conference on Electrical and Computer Engineering of the CCECE, Vancouver, BC, 22-26 April 2007, pp. $1437-1440$. 